\title{
Endogenous Intoxication and the Role of Antioxidants in Motion Activity Correction with Traumatic Brain Injury in Rat Model
}

\author{
Anastasia V. Polozova ${ }^{1,2^{*}}$; Gennady A. Bojarinov ${ }^{2}$; Marina N. Ivashchenko, PhD \\ Aleksandr G. Samodelkin, $\mathrm{PhD}, \mathrm{ScD}^{3}$; Anna V. Deryugina, PhD, ScD ${ }^{1}$ \\ ${ }^{1}$ Lobachevsky State University of Nizhny Novgorod, Nizhny Novgorod, Russia \\ ${ }^{2}$ Privolzhsky Research Medical University, Nizhny Novgorod, Russia \\ ${ }^{3}$ Nizhny Novgorod State Agricultural Academy, Nizhny Novgorod, Russia
}

\begin{abstract}
The aim of this study was to assess the effectiveness of cytoflavin and mexicor in the posttraumatic period of traumatic brain injury (TBI).

Materials and Methods: The experiments were carried out on 60 white non pedigree female rats weighing 180-200 g, with 15 rats in each series. TBI was modeled by a free-falling weight drop of $100 \mathrm{~g}$ from a height of $80 \mathrm{~cm}$ on the parietal-occipital area of the head. Blood samples were taken from the sublingual vein in an amount of $2.0 \mathrm{ml}$ on Days 1, 3, 7, and 12 after the alteration. After TBI, in Group 1, 15 rats received an intraperitoneal injection of 2-ethyl-6-methyl-3-hydroxypyridine succinate (mexicor) for 10 days in a daily dose of $8.0 \mathrm{mg} / \mathrm{kg}$. In Group 2, 15 rats received an intraperitoneal injection of cytoflavin for 10 days in a daily dose of $0.2 \mathrm{ml} / \mathrm{kg}$. The activity of lipid peroxidation and antioxidant protection system in the blood plasma was determined by a biochemicoluminescence method. Analysis of animal motion activity included the determination of the ability to balance and to stay at the wooden bar, time spent for moving on the bar from the bright light source to the darkroom, and paw slip frequency.

Results: Mexicor and cytoflavin decreased the level of oxidative processes in rat model with TBI and the development of secondary brain injury. The positive dynamics in restoring pro- and antioxidant system balance was combined with positive changes in motor function. (International Journal of Biomedicine. 2019;9(1):61-65.)
\end{abstract}

Key Words: traumatic brain injury $\bullet$ rats $\bullet$ lipid peroxidation $\bullet$ antioxidant protection system

\section{Abbreviations}

AOS, antioxidant protection system; $\mathbf{I}_{\max }$ the maximum chemiluminescence intensity; DC, diene conjugate; LPO, lipid peroxidation; LMMWS, low and medium molecular-weight substances; SB, Schiff bases; PSF, paw slip frequency; SBI, secondary brain injury; TAS, total antioxidant status; TBI, traumatic brain injury; TC, triene conjugate.

\section{Introduction}

Traumatic brain injury (TBI) has a high incidence worldwide and is associated with significant morbidity and mortality. According to the Centers for Disease Control, the total combined rates for TBI-related emergency department visits, hospitalizations, and deaths increased in the 2001-2010 decade. ${ }^{(1)}$ The development of body hypoxic state is one of the

*Corresponding author: Anastasia V. Polozova. Lobachevsky State University of Nizhny Novgorod, Nizhny Novgorod, Russia, Nizhny Novgorod, Russia. E-mail: shumilowanastya@gmail.com main factors of acute TBI. In hypoxic state, the energy deficit, to say more exactly ATP deficit, provokes homotypic metabolic and structural changes in various organs and tissues, ${ }^{(2)}$ as well as LPO activation. In turn, LPO products aggravate the disturbance of membrane structure and functions. They play a key role in the beginning and development of brain edema, which is manifested in TBI and may be realized in the disturbance of motion and cognitive function. ${ }^{(3-5)}$

One of the most effective ways to prevent and treat brain traumatic and ischemic lesions is the use of antihypoxic drugs. These are remedies that weaken or nullify hypoxic disturbances. Mexicor and cytoflavin are two such remedies. ${ }^{(6-9)}$ These 
medicines are largely used to manage ischemic conditions. ${ }^{(10-12)}$

The aim of this study was to assess the effectiveness of cytoflavin and mexicor in the posttraumatic period of TBI.

\section{Materials and Methods}

The experiments were carried out on 60 white nonpedigree female rats weighing 180-200g, with 15 rats in each series. All animals were given access to food and water ad libitum. Experiment was performed in accordance with the Order of the Ministry of Health of the Russian Federation №267 (19.06.2003) “On approval of the rules of Good Laboratory Practice» (GLP).

\section{Experimental model of TBI}

The animals were fixed on a plate, and blood was collected from a sublingual vein in an amount of $2.0 \mathrm{ml}$. It was $8 \%-9 \%$ of the circulating blood volume. TBI was modeled by a free-falling weight drop of $100 \mathrm{~g}$ from a height of $80 \mathrm{~cm}$ on the parietal-occipital area of the head. ${ }^{(13)}$ Blood samples were taken from the sublingual vein in an amount of $2.0 \mathrm{ml}$ on Days 1, 3, 7, and 12 after the alteration. Such blood sampling technology simulates the fractional blood loss, which, during the 10 days of the posttraumatic period, was $32 \%-36 \%$ of the volume of circulating blood in the rats.

\section{Treatment}

After TBI, in Group 1, 15 rats received an intraperitoneal injection of 2-ethyl-6-methyl-3-hydroxypyridine succinate (mexicor) for 10 days in a daily dose of $8.0 \mathrm{mg} / \mathrm{kg}$ (a solution for intravenous and intramuscular administration, JSC EkoFarmInvest, Russia). In Group 2, 15 rats received an intraperitoneal injection of cytoflavin for 10 days in a daily dose of $0.2 \mathrm{ml} / \mathrm{kg}$ (a solution for intravenous administration, OOO NTFF Polisan», Russia). In Group 3 (control group-CG), 15 rats received an intraperitoneal injection of physiological saline solution in the same volume. The administration of the drugs was started 1 hour after TBI. The values of the physiological norm of the studied parameters were determined in intact rats $(\mathrm{n}=15)$.
The activity of LPO and ASO in the blood plasma was determined by a biochemicoluminescence method ${ }^{(14)}$ using the biochemiluminometer Lum-5773. The following indices of chemiluminogram were analyzed: total activity of free-radical oxidation $\left(\mathrm{I}_{\max }\right)$ and TAS $(\operatorname{tg} \alpha)$. LPO intensity was defined by the concentration of DC/TC of polyunsaturated fatty acids as well as SB by a spectrophotometry method. ${ }^{(15)}$ using the RF-5301 PC, Shimadzu, (Japan). Each phase was analyzed in comparison with the respective group at the following wavelengths: $220 \mathrm{~nm}$ (isolated double bonds absorption), $232 \mathrm{~nm}$ (DC absorption), $278 \mathrm{~nm}$ (TC absorption), and $400 \mathrm{~nm}$ (SB absorption). The level of DC, TC, and SB was defined by E232/E220, E278/E220, $\mathrm{E} 400 / \mathrm{E} 220$ and it was expressed in terms of relative units (RU).

The distribution index in relation to the content of middle molecules at wavelengths of $238 \mathrm{~nm}, 254 \mathrm{~nm}, 266 \mathrm{~nm}$, and $282 \mathrm{~nm}$ was defined for assessment of LMMWS. ${ }^{(16)}$ The calculation of the final result was made using the formula:

LMMWS $=1.013 \times(8 \times \mathrm{E} 238+16 \times \mathrm{E} 254+44 \times \mathrm{E} 266 / 3+64 \times \mathrm{E} 282 / 3$.

Animal motion activity analysis

The motor disorders were defined by the method of K.Saatman et al. ${ }^{(17)}$ The ability to balance and to stay at the wooden bar, time spent for moving on the bar from the bright light source to the darkroom, and PSF were defined in the posttraumatic period.

The statistical analysis was performed using the statistical software Microsoft Excel. The mean (M) and standard error of the mean (SEM) were calculated. For data with normal distribution, inter-group comparisons were performed using Student's t-test. Differences of continuous variables departing from the normal distribution, even after transformation, were tested by the Mann-Whitney $U$-test. A probability value of $P<0.05$ was considered statistically significant.

\section{Results}

The research results showed that the endointoxication and LPO activation in blood plasma took place in the TBI groups of animals (Table 1).

Table 1.

Parameters of the endointoxication and LPO activation in the TBI posttraumatic period

\begin{tabular}{|l|c|c|c|c|c|c|}
\hline \multirow{2}{*}{ Variable } & \multirow{3}{*}{ Intact rats } & \multirow{2}{*}{ Group } & \multicolumn{4}{|c|}{ Period after TBI (day) } \\
\cline { 3 - 7 } & & & 1 & 3 & 7 & 12 \\
\hline \multirow{3}{*}{$\begin{array}{l}\text { LMMW } \\
\text { RU }\end{array}$} & \multirow{3}{*}{$5.65 \pm 0.43$} & CG & $9.09 \pm 0.55^{*}$ & $8.70 \pm 0.17^{*}$ & $8.78 \pm 0.33^{*}$ & $7.15 \pm 0.4^{*}$ \\
\cline { 3 - 7 } & & Group 1 & $7.69 \pm 0.74^{*}$ & $6.89 \pm 0.50^{\wedge}$ & $6.84 \pm 0.37^{\wedge}$ & $5.70 \pm 0.58$ \\
\cline { 3 - 7 } & & Group 2 & $6.48 \pm 0.28^{\wedge}$ & $6.86 \pm 0.86$ & $5.79 \pm 0.49^{\wedge}$ & $5.24 \pm 0.29^{\wedge}$ \\
\hline \multirow{2}{*}{$\begin{array}{l}\text { I max } \\
\mathrm{mV}\end{array}$} & \multirow{3}{*}{$1.64 \pm 0.14$} & CG & $3.05 \pm 0.14^{*}$ & $2.74 \pm 0.16^{*}$ & $1.97 \pm 0.17$ & $1.93 \pm 0.07$ \\
\cline { 3 - 7 } & & Group 1 & $2.32 \pm 0.11^{* \wedge}$ & $1.98 \pm 0.08^{* \wedge}$ & $1.51 \pm 0.1^{\wedge}$ & $1.27 \pm 0.012^{\wedge}$ \\
\hline & & Group 2 & $2.42 \pm 0.24^{* \wedge}$ & $2.03 \pm 0.1^{* \wedge}$ & $1.33 \pm 0.21^{\wedge}$ & $1.36 \pm 0.24^{\wedge}$ \\
\hline \multirow{2}{*}{$\begin{array}{l}\text { tga, } \\
\mathrm{mV} / \mathrm{sec}\end{array}$} & $3.86 \pm 0.06$ & CG & $3.58 \pm 0.11^{*}$ & $3.56 \pm 0.18$ & $3.41 \pm 0.23$ & $3.31 \pm 0.15$ \\
\cline { 3 - 7 } & & Group 1 & $6.69 \pm 0.51^{* \wedge}$ & $4.87 \pm 0.31^{* \wedge}$ & $4.33 \pm 0.42$ & $4.88 \pm 0.07^{* \wedge}$ \\
\cline { 3 - 7 } & & Group 2 & $6.43 \pm 0.38^{* \wedge}$ & $4.91 \pm 0.31^{* \wedge}$ & $4.59 \pm 0.19^{* \wedge}$ & $4.17 \pm 0.08^{* \wedge}$ \\
\hline
\end{tabular}

$*_{-} P<0.05$ between Group 1/Group 2 and a group of intact rats

$\wedge$ - $P<0.05$ between Group $1 /$ Group 2 and $C G$ 
Mexicor and cytoflavin induced a decrease in the intensity of the intoxication processes. This decrease manifested in a decrease of the plasma LMMWS level in all the stages of the TBI posttraumatic period. The findings showed that mexicor and cytoflavin supressed considerably the endointoxication in blood plasma and induced a decrease in the number of decay products. Besides, after the treatment with these medicaments, the exit of decay products to blood from injured tissues was less intensive.

Activation of free-radical processes and AOS depression were pronounced in the control group. Mexicor and cytoflavin restrained the free-radical oxidative stress. We found a decrease in $I_{\max }$ on Day 3 of the experiment by $28 \%$ in Group 1 and $26 \%$, in Group 2 compared to the value of control gtoup. On Day 7, $\mathrm{I}_{\max }$ in Groups 1 and 2 did not differ from that in the intact rats.

Mexicor and cytoflavin provoked positive changes in freeradical processes in the blood plasma (Table 2). Mexicor induced a decrease in the level of DC and TC on Day 3 of the experiment by $29 \%$ and $44 \%$ relative to CG, respectively. The correction effect of cytoflavin was weaker.
The levels of DG, TC and SB in Group 2 were normalized by Day 7 of the experiment.

We observed tonic and clonic seizures just after TBI for 2-4 sec. Animals lost sensitivity and they had been in a lateral position for 10-20 sec. The study of motor response showed a worsening of motor function up to the end of Day 1 of the experiment (Table 3 ).

The positive dynamics in restoring pro- and antioxidant system balance was combined with changes in motor function. Mexicor and cytoflavin injections induced the normalization of standing balance and walking ability. It manifested in a decrease in PSF as well as in time spent for moving on the bar. At the same time the mexicor effect was more strongly pronounced. PSF decreased by $55.6 \%$ and $44.4 \%$ by the end of Day 1 in Group 1 and Group 2, respectively. The positive dynamics in the motion activity indices was evident up to the end of Day 1 after the mexicor and cytoflavin injections. A significant improvement in motion reactions was registered on Day 3 of the experiment. The level of these indices achieved the intact animal value by Day 7 after the mexicor injection and by Day 12 after the cytoflavin injection.

Table 2.

Changes in the intensity of LPO in the blood plasma of rats in the posttraumatic period

\begin{tabular}{|l|c|l|c|c|c|c|}
\hline \multirow{2}{*}{ Variable } & \multirow{2}{*}{ Intact rats } & \multirow{2}{*}{ Group } & \multicolumn{4}{|c|}{ Period after TBI (day) } \\
\cline { 3 - 7 } & & & 1 & 3 & 7 & 12 \\
\hline \multirow{3}{*}{ DC, RU } & \multirow{3}{*}{$0.12 \pm 0.01$} & CG & $0.22 \pm 0.02^{*}$ & $0.21 \pm 0.02^{*}$ & $0.16 \pm 0.02$ & $0.12 \pm 0.02$ \\
\cline { 3 - 7 } & & Group 1 & $0.16 \pm 0.01^{* \wedge}$ & $0.15 \pm 0.01^{* \wedge}$ & $0.13 \pm 0.02$ & $0.09 \pm 0.01^{*}$ \\
\cline { 3 - 7 } & & Group 2 & $0.17 \pm 0.02^{*}$ & $0.17 \pm 0.03^{*}$ & $0.08 \pm 0.03^{\wedge}$ & $0.08 \pm 0.04$ \\
\hline \multirow{3}{*}{ TC, RU } & \multirow{3}{*}{$0.08 \pm 0.01$} & CG & $0.15 \pm 0.03^{*}$ & $0.16 \pm 0.03^{*}$ & $0.16 \pm 0.02^{*}$ & $0.08 \pm 0.02$ \\
\cline { 3 - 7 } & & Group 1 & $0.12 \pm 0.02$ & $0.09 \pm 0.01^{\wedge}$ & $0.08 \pm 0.03^{\wedge}$ & $0.07 \pm 0.01$ \\
\cline { 3 - 7 } & & Croup 2 & $0.10 \pm 0.02$ & $0.12 \pm 0.01^{*}$ & $0.09 \pm 0.02$ & $0.06 \pm 0.03$ \\
\hline \multirow{3}{*}{ SB, RU } & $8.43 \pm 0.84$ & CG & $9.35 \pm 0.96$ & $12.99 \pm 0.98^{*}$ & $11.06 \pm 0.92^{*}$ & $9.29 \pm 0.75$ \\
\cline { 3 - 7 } & & Group 1 & $10.25 \pm 1.03$ & $8.00 \pm 0.44^{\wedge}$ & $8.03 \pm 1.33$ & $8.25 \pm 0.41$ \\
\cline { 3 - 7 } & Group 2 & $9.89 \pm 0.89$ & $10.94 \pm 0.84^{*}$ & $8.66 \pm 0.64^{\wedge}$ & $8.90 \pm 0.87$ \\
\hline
\end{tabular}

$*_{-} P<0.05$ between Group 1/Group 2 and a group of intact rats

$\wedge_{-} P<0.05$ between Group 1/Group 2 and $C G$

Table 3.

Animal motion activity analysis

\begin{tabular}{|c|c|c|c|c|c|c|}
\hline \multirow{2}{*}{ Variable } & \multirow{2}{*}{ Intact rats } & \multirow{2}{*}{ Group } & \multicolumn{4}{|c|}{ Period after TBI (day) } \\
\hline & & & 1 & 3 & 7 & 12 \\
\hline \multirow{3}{*}{$\begin{array}{l}\text { Moving on } \\
\text { bar, score }\end{array}$} & \multirow{3}{*}{$2.5 \pm 0.1$} & $\mathrm{CG}$ & $6.8 \pm 0.9^{*}$ & $5.7 \pm 0.9^{*}$ & $4.9 \pm 0.5^{*}$ & $4.5 \pm 0.7 *$ \\
\hline & & Group 1 & $4.2 \pm 0.8^{* \wedge}$ & $4.0 \pm 0.4^{*}$ & $2.9 \pm 0.3^{\wedge}$ & $2.6 \pm 0.4^{\wedge}$ \\
\hline & & Group 2 & $4.5 \pm 0.6^{* \wedge}$ & $3.6 \pm 0.3^{* \wedge}$ & $3.3 \pm 0.3^{* \wedge}$ & $2.3 \pm 0.1^{\wedge}$ \\
\hline \multirow{3}{*}{$\begin{array}{l}\text { PSF, } \\
\text { numbers }\end{array}$} & \multirow{3}{*}{$1.0 \pm 0.1$} & $\mathrm{CG}$ & $3.6 \pm 0.7^{*}$ & $2.8 \pm 0.6^{*}$ & $2.0 \pm 0.5$ & $2.2 \pm 0.5^{*}$ \\
\hline & & Group 1 & $1.6 \pm 0.7$ & $1.3 \pm 0.4$ & $1.1 \pm 0.2$ & $0.8 \pm 0.2^{\wedge}$ \\
\hline & & Group 2 & $2.0 \pm 0.4^{*}$ & $1.7 \pm 0.3^{*}$ & $1.5 \pm 0.3$ & $1.0 \pm 0.1^{\wedge}$ \\
\hline \multirow{3}{*}{$\begin{array}{l}\text { Time spent } \\
\text { for moving } \\
\text { on the bar, } \\
\text { score }\end{array}$} & \multirow{3}{*}{$1.5 \pm 0.1$} & $\mathrm{CG}$ & $3.4 \pm 0.4^{*}$ & $2.9 \pm 0.3^{*}$ & $2.2 \pm 0.2 *$ & $2.0 \pm 0.4$ \\
\hline & & Group 1 & $1.8 \pm 0.2^{\wedge}$ & $1.6 \pm 0.2^{\wedge}$ & $1.4 \pm 0.2^{\wedge}$ & $1.4 \pm 0.2$ \\
\hline & & Group 2 & $1.9 \pm 0.2^{\wedge}$ & $1.8 \pm 0.1^{* \wedge}$ & $1.8 \pm 0.2$ & $1.4 \pm 0.1$ \\
\hline
\end{tabular}

*. $P<0.05$ between Group 1/Group 2 and a group of intact rats

$\wedge-P<0.05$ between Group 1/Group 2 and $C G$ 


\section{Discussion}

Our results showed that mexicor and cytoflavin decreased the level of oxidative processes with TBI and the development of secondary brain injury. Secondary brain injury represents the cascade of biochemical inflammatory stress reactions, which provoke brain ischemia and worsen considerably the severity of the general condition. These reactions also hinder the restoration of psychical and moving activity. ${ }^{(18)}$ In addition, the processes of neuroregeneration and neuroprotection start at the same time as the secondary brain injury cascade. Specific intracellular neuroregulatory proteins and pluripotent stem cells, being neurotrophic factors, play a key role in these processes. However, in TBI (especially, in severe cases) the regeneration function of nerve tissue gives way to the processes of secondary brain injury because the site of primary brain injury is too large and the total body reactivity decreases; thus, the speed of the development of secondary brain injury is higher than that of the reparative processes.

The mexicor and cytoflavin injections in the posttraumatic period of TBI induced a decrease in endointoxication and oxidative stress by increasing the antioxidative blood potential in all stages of the experiment. These medications interrupted the formation of Schiff bases at the level of diene- and triene conjugates. Mexicor was the most effective in the first stage of the posttraumatic period (1-3 days after TBI). Probably, differences between effect manifestations are associated with differences in the composition of these "succinate" medications. Mexicor is a heteroaromatic antioxidant, in which the succinate is connected by covalent link with antioxidant emoxypine. ${ }^{(6)}$ Cytoflavin is a complex preparation, the composition of which comprises the following components: succinate acid, riboflavin, riboxinum, and nicotinamide. ${ }^{(20)}$ Earlier it was shown that this group of preparations decreases the intensity of LPO both in blood plasma and in cell membranes. ${ }^{(21)}$

It is very important to note that mexicor and cytoflavin promoted a decrease in the LMMWS content. The catabolic component of LMMWS is represented by low molecular weight compounds-protein breakdown products. The catabolic anabolic component of LMMWS is represented by a complex of peptide compounds - protein proteolysis products. Peptide compounds are similar by their structure to regulatory peptides, and they may provoke abnormality in the metabolism and function of cells. They may also provoke the appearance of drug resistance by blocking T-cell receptors. The study results showed that cytoflavin and mexicor restored the functioning of cell membranes due to antioxidant properties and decreasing LMMWS on the surface of the membranes. A decrease in LMMWS content is evidence of reduced inflammation.

Given that mexicor and cytoflavin are succinic acid drugs, it is possible to suppose that the restoration of metabolism in the cells involves restoring homeostasis. The restoration of movement function of the experimental animals proves this thesis. Thus, it can be concluded that mexicor and cytoflavin are multimodal drugs with neuroprotective, antioxidant and anti-inflammatory properties.

\section{Conflict of Interest}

The authors declare that they have no competing interests.

\section{Acknowledgments}

The reported study was funded by RFBR according to the research project № 18-34-00831.

\section{References}

1. Galgano M, Toshkezi G, Qiu X, Russell T, Chin L, Zhao LR. Traumatic Brain Injury: Current Treatment Strategies and Future Endeavors. Cell Transplant. 2017;26(7):1118-1130. doi: 10.1177/0963689717714102.

2. Boyarinov GA, Deryugina AV, Yakovleva EI, Zaitsev RR, Shumilova AV, Bugrova ML, et al. Pharmacological correction of microcirculation in rats suffering from traumatic brain injury. Cell and Tissue Biology. 2017;11(1):65-72.

3. Bar-Or D, Bar-Or R, Rael LT, Brody EN. Oxidative stress in severe acute illness. Redox Biol. 2015;4:340-5. doi: 10.1016/j.redox.2015.01.006.

4. Quillinan N, Herson PS, Traystman RJ. Neuropathophysiology of Brain Injury. Anesthesiol Clin. 2016;34(3):453-64. doi: 10.1016/j.anclin.2016.04.011.

5. Stephens JA, Salorio CE, Gomes JP, Nebel MB, Mostofsky SH, Suskauer SJ. Response Inhibition Deficits and Altered Motor Network Connectivity in the Chronic Phase of Pediatric Traumatic Brain Injury. J Neurotrauma. 2017;34(22):31173123. doi: 10.1089/neu.2017.5081.

6. Golikov AP, Mikhin VP, Bŏ̌tsov SA, Bogoslovskaia EN, Vesel'eva NV, Luk'ianov MM, Rudnev DV, Frolov AA. [Efficacy of cytoprotective agent Mexicor in urgent cardiology]. Ter Arkh. 2004;76(4):60-5. [Article in Russian].

7. Bojarinov GA, Kotlov IS, Brichkin JuD. xEfficiency of cytoprotectors in the prevention of reperfusion syndrome in patients with myocardial infarction in the thrombolytic therapyъ. Poliklinika. 2010;(6):110-116. [Article in Russian]. 8. Shulginova AA, Konoplya AI, Bystrova NA. Disorders of the immune status in patients with chronic cerebral ischemia; differentiated pharmacological correction. Research Results in Pharmacology. 2018;4(2):105-123.

9. Cherniy VI, Andronova IA, Gorodnik GA, Nazarenko VK, Cherniy TV. [The role and place of cytoflavin in the management of severe traumatic brain injury]. Journal of Neuroscience of B.M. Mankovsky. 2015;(3):21-33. [Article in Russian].

10. Volchegorskii IA, Rassokhina LM, Miroshnichenko IY. [Cerebroprotective effects of emoxipin, reamberin, and mexidol in alloxan diabetes]. Bull Exp Biol Med. 2013;155(1):56-64.

11. Shakhmardanova SA, Gulevskya ON, Khananashvili YaA, Zelenskaya AV, Nefedov DA, Galenko-Yaroshevsky PA. [Succinic and fumaric acid drugs for prevention and treatment of various diseases]. Journal of Fundamental Medicine and Biology 2016;(3):16-30. [Article in Russian].

12. Firsov AA. New aspects of modern cytoprotector therapy on the example of experience of the clinical use of «Mexikor» preparation. Sovremennaya Meditsina. 2017;5:110-112. [Article in Russian].

13. Tsymbalyuk VI, Kochin OV. Experimental modeling 
of traumatic brain injury. Ukrainian Neurological Journal. 2008;2:10-12. [Article in Russian].

14. Kuz'mina EI, Nelyubin AS, Shchennikova MK. [The use of induced chemiluminescence to evaluate free radical reactions in biological substrates]. Mezhvuzovskij sbornik biohimii i biofiziki mikroorganizmov. 1983:179-183. [Article in Russian].

15. Volchegorskiı̆ IA, Nalimov AG, Iarovinskiı̆ BG, Lifshits RI. [Comparison of various approaches to the determination of the products of lipid peroxidation in heptane-isopropanol extracts of blood]. Vopr Med Khim. 1989;35(1):127-31. [Article in Russian].

16. Malakhova MYa. [Endogenous intoxication as a reflection of compensatory restructuring of metabolic processes in the body]. Efferentnaya Terapiya, 2000;34:3-14. [Article in Russian]. 17. Saatman KE, Murai H, Bartus RT, Smith DH, Hayward NJ, Perri BR, McIntosh TK. Calpain inhibitor AK295 attenuates motor and cognitive deficits following experimental brain injury in the rat. Proc Natl Acad Sci U S A. 1996;93(8):3428-33. 18. Reed AR, Welsh DG. Secondary injury in traumatic brain injury patients - a prospective study. S Afr Med J. 2000;92(3):221-4.

19. Ekdahl CT. Microglial activation - tuning and pruning adult neurogenesis. Front Pharmacol. 2012;3:41. doi: 10.3389/ fphar.2012.00041.

20. Antipenko EA, Derugina AV, Gustov AV. [An effect of cytoprotective therapy on stress resistance and compensatory abilities of patients with chronic cerebral ischemia]. Zh Nevrol Psikhiatr Im S S Korsakova. 2015;115(12):74-78. doi: 10.17116/jnevro201511511274-78. [Article in Russian]. 21. Deryugina AV, Shumilova AV, Filippenko ES, Galkina YV, Simutis IS, Boyarinov GA. Functional and Biochemical Parameters of Erythrocytes during Mexicor Treatment in Posttraumatic Period after Experimental Blood Loss and Combined Traumatic Brain Injury. Bull Exp Biol Med. 2017;164(1):26-29. doi: 10.1007/s10517-017-3918-4. 